\title{
POLÍTICAS PÚBLICAS Y \\ EL FRACASO ESCOLAR: \\ UN ANÁLISIS CONCEPTUAL \\ Y APLICADO AL PRIMER \\ CICLO DE LA EGB \\ PARA ESTABLECIMIENTOS \\ SELECCIONADOS DE \\ LA CIUDAD DE SANTA FE
}

\author{
Tesista: \\ Roberto César Amor \\ Director de Tesis: \\ Edith Depetris
}

\section{MARCO TEÓRICO}

El nivel de desarrollo de un país encuentra explicación en función de sus recursos naturales, de capital físico, de capital humano, su capacidad tecnológica y la calidad de sus organizaciones e instituciones. Existe, consecuentemente, una razonable asociación entre desarrollo económico y capital humano. La educación, entendida como la actividad a través de la cual se produce y se distribuye el conocimiento, asume una importancia prioritaria que justifica la intervención del Estado en la fijación de las políticas respectivas.

La escuela, como esfuerzo consciente y deliberado, esto es, como política pública, es el recurso de aquellos que no disponen de herencias o de otros medios para apropiarse de los frutos de la ciencia y la tecnología y de los bienes que les están asociados. Por eso se necesita una pedagogía adecuada, para dar más a quienes menos tienen en materia de bienes culturales.
La importancia de la educación primaria en particular se confirma cuando se tienen en cuenta las externalidades que derivan de la apropiación del conocimiento, aprovechamiento de las capacidades, fijación de valores y cambio de actitudes. Para lograr el máximo beneficio para la sociedad en conjunto, la primera prioridad de la educación como política pública es que toda la población adquiera aptitudes básicas.

A nivel individual la adquisición de conocimientos genera la preparación necesaria para el desempeño del individuo en el marco social en el que le competa desenvolverse. Desde el punto de vista de la sociedad, distintas investigaciones asocian el capital humano al crecimiento económico, mejoramiento de la salud y la reducción de la pobreza.

Si tenemos en cuenta el carácter acumulativo de la educación, habremos de reparar en la importancia que merece asignarse a los co- 
nocimientos básicos, sin los cuales se cierran las puertas de acceso a estadios superiores.

No alcanzar los objetivos pedagógicos del nivel, la repitencia, desgranamiento y deserción escolar son las manifestaciones más evidentes del fracaso escolar.

De allí que resulte interesante analizar métodos y medios para determinar prioridades tendientes a mejorar la calidad educativa y como forma expresa de combatir el fracaso escolar.

Abordado el fracaso escolar desde las políticas sociales, debe permitirnos conocer qué margen de maniobra tiene el Estado ante una realidad determinada por recursos físicos y tecnológicos, disponibilidad presupuestaria, planta docente, capacitación docente y una demanda creciente de servicio en cantidad por aplicación de la Ley Federal de Educación, que a su vez debe responder por razones de justicia al principio de equidad.

\section{OBJETIVOS}

El presente trabajo tiene como objetivos, en primer lugar, delimitar y encuadrar conceptualmente -desde la perspectiva de las políticas públicas para la educación- el problema del fracaso escolar en todas sus manifestaciones. En segundo lugar, explorar cómo se manifiesta el fracaso escolar en el caso concreto de establecimientos seleccionados de la ciudad de Santa Fe. Por último, reflexionar sobre las posibilidades futuras de acceder a líneas de acción que permitan definir alternativas tendientes a superar el fracaso escolar.

\section{METODOLOGİA}

Para el análisis requerido en este trabajo se recurrió en primer lugar a fuentes documentales, bibliográficas y jurídicas, tanto argentinas como comparadas.

En segundo lugar, para explorar cómo se da la problemática en algunos establecimientos de nuestro medio, se realizaron entrevistas a maestros al frente de grados correspondien- tes al primer ciclo de la Educación General Básica y a los directores, quienes a su vez confeccionaron una planilla general por escuela donde se brindan datos de amplitud prestacional e información sobre repitentes, movimiento de matrícula y rendimiento pedagógico.

A tal fin, se seleccionaron seis establecimientos escolares -cuatro oficiales y dos privados- de la ciudad de Santa Fe, que reciben a niños pertenecientes a barrios urbano-marginales.

También se verifica la aplicación de planes específicos por parte del Gobierno Provincial en relación con los establecimientos analizados.

\section{PRINCIPALES RESULTADOS}

El estudio evidencia que las premisas sostenidas son válidas y se fundan en comprobaciones realizadas.

El alto grado de matriculación y el gran número de niños por maestros dificultan el proceso de enseñanza-aprendizaje y facilitan las condiciones que conllevan al fracaso escolar.

El porcentaje de alumnos que repiten es mayor en los primeros grados y, como consecuencia, aparecen los casos de sobreedad que provoca desajustes de conductas que inciden negativamente en el proceso pedagógico.

La tarea compensatoria que aborda el Estado, en el aspecto social, brindando en horario escolar los servicios de copa de leche y comedor escolar, reduce sensiblemente los espacios de tiempo dedicados a las tareas específicas docentes tendientes a lograr los objetivos cognitivos del nivel.

La formación básica docente es limitada y destinada a un "estándar" de niño distinto del que en la mayoría de los casos llega a la escuela desde un barrio urbano-marginal, lo que resta herramientas que permitan abordar el fracaso escolar.

El docente, al considerar que la problemática del fracaso escolar tiene su explicación desde la perspectiva del reduccionismo psicoló- 
gico o bien desde la reproducción social de la escuela, genera parálisis de acción a nivel institucional para abordar soluciones.

\section{CONCLUSIONES}

El estado orientador de los sistemas de prestación de servicios sociales de interés público deberá inexcusablemente reunir varias condiciones para ser efectivo. Al diseño institucional previsto y a las competencias técnicas y humanas indispensables para cumplir con sus funciones habrá que agregar los recursos financieros necesarios y medir logros efectivos en materia de adquisición de conocimientos y, en su caso, producir las intervenciones necesarias que permitan corregir distorsiones en materia de equidad y calidad.

Calidad educativa y fracaso escolar, en términos de políticas públicas parecen ser ambas caras de una misma moneda.

Se sugiere abordar un proyecto tendiente a combatir el fracaso escolar, a partir de estrategias basadas en la participación de todos los actores involucrados que permitan devolver a la escuela su función genuina, participación crítica y organizativa, de modo que la vinculación de los procesos educativos y los procesos sociales hagan posible una educación que reduzca la discriminación y rescate las potencialidades de aprendizaje de los alumnos.
Dicho proyecto debería estipular metas en cuanto a la disminución progresiva de la repitencia, deserción y desgranamiento en términos cuantitativos, al margen de establecer una propuesta didáctica que permita evaluar en términos cualitativos, mensurable a través de pruebas a los alumnos, un mejoramiento en el proceso de enseñanza-aprendizaje. Debería seleccionarse las escuelas urbanos-marginales donde precisamente los factores críticos se vinculan a una escasa participación de la comunidad en la gestión educativa, formación docente inadecuada para la atención de la diversidad y necesidades básicas insatisfechas del grupo familiar al que pertenecen los alumnos.

Debería preverse la intervención de los Institutos de Formación Docente, que podrían coordinar el accionar multidisciplinario en cada unidad operativa en la que se constituirían las escuelas. con la participación de sus directivos y cuadros docentes, instituciones coescolares, profesores de práctica y alumnos practicantes de esos Institutos y representantes de las organizaciones no gubernamentales que integren el proyecto.

En ese marco participativo, con políticas públicas socialmente aceptadas, es posible contar con un Proyecto Educativo Institucional que atienda la demanda concreta de la comunidad en que se encuentra ubicada la escuela. 


\section{BIBLIOGRAFÍA}

Banco Mundial. Prioridades y estrategias para la educación. El desarrollo en la práctica. 1996.

Echeverri, G. (1999): La tragedia educativa. Fondo de Cultura Económica. Argentina.

Filmus, D. (1999): Estado, sociedad y educación en la Argentina de fin de siglo. Procesos y desafíos. Troquel.

Narodowsky, M. (1996): La escuela de fin de siglo. Entre la informática y la merienda reforzada. Ediciones Novedades Educativas. Buenos Aires.

Tedesco, J. C. (1995): El nuevo pacto educativo. Educación, competitividad y ciudadanía en la sociedad moderna. Alauda-Anaya. Madrid.

Tenti, E. (1995): La escuela vacía. Deberes del Estado y responsabilidades de la sociedad. UNICEF-Losada. Buenos Aires.

UNESCO. Informe Regional. Instituto de Estadística. América Latina y Caribe. 2001. 